Recebido em 09/2018. Aceito para publicação em 09/2019.

\title{
EXPERIÊNCIAS DO PIBID QUE AUXILIAM NA MELHORIA DO RENDIMENTO ESCOLAR
}

\section{PIBID EXPERIENCES THAT HELP IMPROVING SCHOOL PERFORMANCE}

\author{
Irene Coelho de Araujo ${ }^{1}$ \\ Marco Aparecido Queiroz Duarte ${ }^{2}$ \\ Regina Litz Lamblém ${ }^{3}$ \\ Eder Pereira Neves ${ }^{4}$
}

Resumo: O programa institucional de bolsa de iniciação a docência (PIBID), criado em 2009 pelo Ministério da Educação, busca inserir o estudante de licenciatura em seu futuro ambiente de trabalho durante seu processo de formação, dividido em subprojetos por cursos de graduação. Este trabalho tem como objetivo relatar experiências vivenciadas em atividades desenvolvidas no PIBID em um subprojeto de matemática ao longo de 7 anos. Durante este período de execução foram desenvolvidas atividades envolvendo acadêmicos, professores e alunos de três escolas estaduais do município de Cassilândia-MS. Para avaliar os efeitos das ações nos envolvidos no PIBID foi usada a metodologia da observação participante por meio de informações e experiências anotadas e discutidas nos encontros entre coordenadores, acadêmicos e supervisores do PIBID. Estas atividades colaboraram com a formação docente dos acadêmicos, pois aproximaram a universidade da escola, criando um ambiente favorável ao ensino e melhoria de rendimento escolar dos alunos das escolas participantes.

Palavras-chave: Ensino e aprendizagem; experiências acadêmicas; formação de professores.

Abstract: The institutional program of Teaching Initiation Scholarship (PIBID), created in 2009 by the Ministry of Education, aims to insert undergraduate students in their future work environment during their training process, divided into subprojects by undergraduate courses. This paper aims to report experiences lived in the PIBID activities in a subproject of mathematics over 7 years. During this period of execution, activities were developed involving academics, teachers and students from three state schools in Cassilândia-MS. In order to evaluate the effects of the actions on those involved in the PIBID, the methodology of participant observation was used by information and experiences annotated and discussed in the meetings among coordinators, academics and supervisors of PIBID. These activities collaborated with the teacher formation of the students, since they brought the university closer to the school, creating a favorable environment for teaching and improvement of scholastic performance of the students from the participating schools.

Keywords: Teaching and learning; academic experiences; teacher training.

\section{INTRODUÇÃO}

O Programa Institucional de Bolsa de Iniciação à Docência (PIBID) é um programa do Ministério da Educação, gerenciado pela Coordenação de Aperfeiçoamento de Pessoal de Nível Superior (CAPES), que tem como objetivo principal o incentivo à formação de professores para a Educação Básica e a elevação da qualidade da escola

\footnotetext{
1 Universidade Estadual de Mato Grosso do Sul - UEMS, Brasil. E-mail: irene@uems.br.

2 Universidade Estadual de Mato Grosso do Sul - UEMS, Brasil. E-mail: marco@uems.br.

3 Universidade Estadual de Mato Grosso do Sul - UEMS, Brasil. Brasil. E-mail: lamblem@uems.br.

${ }^{4}$ Universidade Estadual de Mato Grosso do Sul - UEMS, Brasil. E-mail: ederpereira@uems.br
} 
pública. O PIBID, que teve início em âmbito nacional em 2009, é uma iniciativa para o aperfeiçoamento e a valorização da formação de professores para a Educação Básica. O Programa concede bolsas a alunos de licenciatura participantes de projetos de iniciação à docência desenvolvidos por Instituições de Ensino Superior (IES) em parceria com escolas de Educação Básica da rede pública de ensino. Os projetos devem promover a inserção dos estudantes no contexto das escolas públicas desde o início da sua formação acadêmica para que desenvolvam atividades didático-pedagógicas sob orientação de um docente da licenciatura e de um professor da escola (BRASIL, 2014).

Esta inserção, em geral, possibilita ao universitário uma melhor decisão sobre o seu futuro como professor, pois este passa a vivenciar a rotina escolar. Os acadêmicos bolsistas do PIBID participam de várias atividades na escola em que são inseridos, tais como: observações de aulas, reuniões pedagógicas e de pais e mestres, preparação de atividades e materiais didático-pedagógicos e apresentação de materiais e jogos. Essas atividades proporcionam aos acadêmicos bolsistas do PIBID uma convivência com alunos, professores, diretores e demais funcionários da escola. Permitindo-lhes ter todas as informações necessárias a respeito da profissão que pretendem seguir.

Relatos mostram a importância do PIBID na formação acadêmica, proporcionando melhorias na formação de professores de matemática e também contribuindo para a formação continuada dos professores das escolas participantes (SARTORI; SCUCK; BURIN, 2012; MARIN; FRANCO, 2014), de física (MIQUELIN, 2014), de química (BRAIBANTE; WOLLMANN, 2012), pedagogos (CAVALHEIRO et al., 2012), e de outras licenciaturas, como ciências biológicas, geografia, história e letras (ARANDA, 2011). Além disso, há ações dos subprojetos do PIBID de diversas formas: no combate ao bullying (MELO et al., 2013) no trabalho e mudança de atitudes de supervisores (CAMARGO, 2013), na percepção da matemática como conteúdo curricular por estudantes de ensino fundamental (SILVA, 2013), na preparação para a OBMEP e para - ENEM e inclusão de alunos com deficiência visual (CAPPELIN; SALOMÃO; BEJARANO, 2011), no resgate da função da escola como criadora de oportunidades de realização profissional (NEITZEL; FERREIRA; COSTA, 2013).

No Curso de Matemática da Universidade Estadual de Mato Grosso do Sul (UEMS), Campus de Cassilândia, o PIBID se iniciou em 2011. No início, entre 2011 e 2013, os acadêmicos bolsistas do PIBID foram inseridos apenas em uma escola estadual. A partir do início de 2014, com o aumento do número de bolsistas, mais duas escolas foram acrescentadas.

O subprojeto do PIBID de Matemática da UEMS, Campus de Cassilândia, atua de acordo com as orientações nacionais (BRASIL, 2014) - visando a melhoria na formação dos acadêmicos participantes e criando situações para que estes possam admitir como certas suas decisões por ser professores, além de contribuir com as escolas envolvidas. Assim, as ações do subprojeto de Matemática procuraram colocar acadêmicos e demais participantes próximos da prática da matemática do dia a dia, mostrando-lhes a utilidade 
do que estava sendo estudado e ajudando-Ihes na organização dos seus pensamentos por meio dos estudos realizados, corroborando com o pensamento de Carraher, Carraher e Schlemann (1989, p.11), que afirmam que: "a matemática que um sujeito produz não é independente de seu pensamento enquanto ele a produz, mas pode vir a ser cristalizada e tornar-se parte de uma ciência, a matemática, ensinada na escola e aprendida dentro e fora da escola".

As ações do PIBID buscaram também auxiliar os professores das escolas participantes, "por meio do estabelecimento de propostas contributivas às necessidades desses professores para suprir seus anseios e disponibilizar ajuda para solução dos problemas reais que enfrentam no cotidiano da sala de aula" (SOUZA; ESTEVEZ, 2011, p. 27).

Suas ações estiveram totalmente voltadas para o professor em formação e o aluno do ensino básico também em formação, buscando mostrar a importância dos dois na educação brasileira.

No cenário educacional muitos são os que assumem papéis e funções em níveis diversos. Todavia, mesmo não ocupando altos cargos e não participando do processo principal de decisões, certamente é o professor uma das duas figuras mais importantes. A outra, sem dúvida, é o aluno. Embora se possa dizer que no processo interativo entre professor e aluno, um exerce influência sobre o outro, cabe ao professor influir mais no processo de formação e desenvolvimento dos alunos que the são confiados, sejam eles crianças do maternal ou mesmo universitários (WITTER, 2013, p. 34).

No PIBID, o acadêmico bolsista convive com as duas figuras mais importantes de uma escola na opinião de Witter (2013) e conhece as características desta relação.

Ponte e Quaresma (2015) destacam que diante das dificuldades dos alunos, constata-se a necessidade de leituras, diálogos entre os profissionais, novas metodologias na apresentação dos conteúdos, valorização do que o aluno sabe, ou seja, o acadêmico deve compreender que todos os alunos merecem respeito, atenção, diferentes formas de apresentação de conceitos, etc. Assim, o acadêmico deve ficar atento no desenvolvimento de suas atividades no subprojeto para que tenha condições de conhecer a profissão de perto e avaliar se quer ou não segui-la.

Com o desgaste e a desvalorização da profissão, além das várias atribuições que são continuamente dadas ao professor, dentre elas a de resolver problemas sociais que os pais dos alunos não conseguem resolver, problemas de saúde têm tomado conta da carreira de alguns docentes. Para Witter (2013), muitas queixas são ouvidas e debatidas por diferentes profissionais, mas, cada vez mais os professores estão se afastando das salas de aula.

$\mathrm{Na}$ escola, o trabalho mais diretamente vinculado à produção é o realizado pelo professor, daí a maior pressão do sistema incidir sobre ele. O resultado da produção é constituído pelo que se constata no 
aluno em termos do desenvolvimento de competências e de habilidades estabelecidas e interligadas nos objetivos da escola. Esta situação pode gerar muito estresse no professor (WITTER, 2013, p. 35).

Além dos problemas acima citados, o professor de matemática precisa lidar com as dificuldades de aprendizagem de matemática, devido ao fato dela ser considerada por muitos um assunto de difícil compreensão e, na concepção do aluno de ensino básico, com poucas aplicações no cotidiano.

Diante deste cenário que o professor vivencia está o acadêmico bolsista do PIBID, percebendo toda a sua ansiedade e angústia, com pressão por parte de alunos, pais, coordenadores, diretores e dele mesmo, pois, quer obter sucesso no ensino e, muitas vezes, culpa a si próprio por não conseguir alcançar bons resultados na aprendizagem dos alunos.

O objetivo deste trabalho é relatar experiências vivenciadas em atividades do PIBID a fim de contribuir com aqueles que trabalham com o ensino de matemática, principalmente com subprojetos do PIBID. Para isso, algumas das atividades desenvolvidas são descritas.

As atividades desenvolvidas tinham como proposta promover discussões sobre a importância da matemática, reforçando conceitos fundamentais por meio de situações contextualizadas. Além de promover a interação escola e universidade, o subprojeto proporcionou a formação continuada dos professores regentes de matemática das 3 escolas estaduais conveniadas do município de Cassilândia-MS.

Ao longo dos 7 anos, passaram pelo subprojeto de Matemática do PIBID 4 coordenadores de área (Professores universitários selecionados para coordenar 0 subprojeto), 5 supervisores (Professores da educação básica selecionados para supervisionar os pibidianos nas escolas participantes), cerca de 200 graduandos (pibidianos), considerando as trocas de bolsistas nesse período. Além da colaboração de diretores, coordenadores e professores de matemática das escolas participantes, totalizando 25 pessoas. Durante a realização das atividades, somando momentos de observações, e de reforço em contraturno, o subprojeto pode atender aproximadamente 5000 alunos dos Ensinos Fundamental e Médio.

A metodologia utilizada durante todo o desenvolvimento do subprojeto foi a observação participante. Usando, para tanto, um caderno de anotações das observações e reflexões, para possíveis discussões, com objetivo de avaliar as atitudes dos alunos nas apresentações e desenvolvimento das atividades, por meio da participação, grau de satisfação e relatos das experiências vivenciadas pelos envolvidos em tais ações.

A observação participante exerce papel importante nas pesquisas qualitativas, já que: 
O tipo característico dos estudos qualitativos, porém, é a observação não estruturada, na qual os comportamentos a serem observados não são predeterminados, eles são observados e relatados da forma como ocorrem, visando descrever e compreender o que está ocorrendo numa dada situação. Esta é a forma por excelência, da observação participante, uma das técnicas mais utilizadas pelos pesquisadores qualitativos. Na observação participante, o pesquisador se torna parte da situação observada, interagindo por longos períodos com os sujeitos, buscando partilhar o seu cotidiano para sentir o que significa estar naquela situação. A importância atribuída à observação participante está relacionada à valorização do instrumental humano, [...] (ALVES-MAZZOTTI; GEWANDSZNAJDER, 1999, p. 166-167).

As informações e experiências anotadas no caderno e discutidas nos encontros com os bolsistas são descritivas, na tentativa de perceber como ocorrem as atividades na prática diária de cada acadêmico bolsista do PIBID para o aperfeiçoamento do projeto. Por meio do amadurecimento das respostas às questões levantadas nestas observações e discutidas em grupo ou individualmente foi possível avaliar cada atividade desenvolvida dentro do subprojeto de matemática, e, quando necessário replanejá-las.

O restante do trabalho é organizado da seguinte forma: na Seção 2 são descritas algumas das atividades desenvolvidas no subprojeto de matemática do PIBID da UEMS de Cassilândia; na Seção 3 estão os resultados e discussões a respeito das atividades relatadas e na Seção 4 são tecidas as considerações finais.

\section{DESENVOLVIMENTO - Atividades Desenvolvidas no PIBID}

Alguns procedimentos metodológicos utilizados nas capacitações aos bolsistas do PIBID foram desenvolvidos por meio das concepções e características de uma Atividade Orientadora de Ensino proposta por Moura et al. (2010).

\footnotetext{
Para que a aprendizagem se concretize para os estudantes e se constitua efetivamente como atividade, a atuação do professor é fundamental ao mediar a relação dos estudantes com o objeto do conhecimento, orientando e organizando o ensino. As ações do professor na organização do ensino devem criar, no estudante, a necessidade do conceito, fazendo coincidir os motivos da atividade com o objeto de estudo. O professor, como aquele que concretiza objetivos sociais objetivados no currículo escolar, organiza o ensino: define ações, elege instrumentos e avalia o processo de ensino e aprendizagem (MOURA et al., 2010, p. 216).
}

Ao conceber uma atividade orientadora de ensino como algo que proporciona êxitos, é possível perceber que o professor e o aluno estão focados no ato de ensinar e aprender, desta forma, o aluno está sempre disposto a apreender os conceitos ensinados pelo professor, por isso, há um maior interesse de sua parte em permitir ao professor a utilização de variadas formas de proporcionar o ensino de determinado conceito. 
Os professores e os acadêmicos bolsistas do PIBID organizaram as suas ações e atividades de acordo com as necessidades dos seus alunos. Por meio de uma avaliação diagnóstica foi possível identificar as dificuldades relacionadas aos conteúdos matemáticos que os alunos participantes das atividades das escolas envolvidas apresentavam. A partir desse levantamento de necessidades foi feito o planejamento das atividades e a escolha dos recursos necessários para apresentação dos conteúdos. A apresentação dos conteúdos aos alunos participantes foi de forma dinâmica e contextualizada, utilizando variados recursos, com os acadêmicos bolsistas do PIBID sendo mediadores do conhecimento.

Nos encontros de capacitações foram discutidas as características das atividades apresentadas aos alunos, fazendo debates sobre a prática do professor em sala de aula, trocas de experiências, análise e simulações de situações, discussões sobre conceitos matemáticos e as formas de apresentação, confecção e apresentação de materiais didáticos, discussão sobre planejamento e apresentação de roteiros de aulas, análise e discussões sobre vídeos, imagens, filmes, dinâmicas de grupo, desenvolvimento de atividades, leitura de textos, etc.

A forma de desenvolver as atividades com os acadêmicos foi estruturada de maneira simultânea ou sequencial, oferecendo a oportunidade de conhecer, discutir e analisar o assunto sob diversos olhares, de modo que eles ficassem à vontade para expressarem suas opiniões, suas dúvidas e suas contribuições que pudessem auxiliar na sua prática, na dos seus colegas e na aprendizagem dos seus alunos.

O processo de avaliação foi feito em cada encontro com os bolsistas, por meio de conversas com os participantes, ouvindo os seus anseios, suas dúvidas e verificando a necessidade de mudança de atitudes. Questionamos, também, os professores supervisores das escolas envolvidas para verificarmos a satisfação ou não deles em relação às atitudes do acadêmico. Se o projeto não estivesse atendendo as necessidades e expectativas propostas, eram feitas novas reflexões sobre seus objetivos e procedimentos para colocá-los em prática da melhor forma possível.

Com base nos dois parágrafos anteriores, pode-se dizer que as atividades do PIBID envolveram os coordenadores do projeto, professores supervisores, acadêmicos e alunos das escolas participantes. Estas atividades passaram por quatro fases: planejamento, elaboração, execução e reflexão. No planejamento as atividades foram sugeridas e planejadas pelos participantes. Ainda no planejamento, eram escolhidos os membros da equipe que executariam as atividades. Na elaboração, os participantes confeccionavam e/ou selecionavam materiais para a execução das atividades. A execução era o momento em que as atividades eram realizadas junto com os alunos das escolas participantes. Por fim, na fase de reflexão, o grupo se reunia para avaliar o impacto das atividades sobre o público alvo e os ajustes que deveriam sofrer se fossem repetidas com o mesmo grupo de alunos ou apresentadas para outros alunos. Nem todas as atividades passavam por esse processo, mas todas, antes de sua execução 
pelos acadêmicos, eram pensadas por coordenadores e supervisores. Algumas atividades realizadas no PIBID serão relatadas a seguir.

\section{Atividade 1 - Observações de aulas}

Esta atividade tinha como objetivo inserir os graduandos na rotina das salas de aula, para que pudessem conhecer a postura do professor, as formas de apresentação de conteúdos, ações e reações na relação aluno professor de matemática.

Para as observações de aulas, geralmente, eram escolhidos acadêmicos bolsistas do PIBID da primeira série, pois coordenadores e supervisores concordavam que esses alunos precisavam de um contato inicial com a sala de aula. Esta atividade também teve como objetivo uma revisão de conteúdo, pois acompanhavam os conceitos matemáticos discutidos nas aulas. Além disso, auxiliavam o professor, acompanhando os alunos na resolução de exercícios em grupos. Dessa atividade participaram 60 graduandos e cerca de 4000 alunos das escolas participantes.

Mesmo sendo acadêmicos com idades diferenciadas e nenhuma experiência docente em sala de aula, havia pontos em comum nos seus relatos orais sobre a observação em sala de aula. Em geral, a maioria deles relatava sobre a forma como os alunos agiam e reagiam em determinadas situações e sobre suas atitudes negativas alunos desinteressados, que não levavam cadernos e livros didáticos para a escola, que ficavam conversando sobre outros assuntos, que desrespeitavam o professor, que não se concentravam ao fazer as avaliações, etc. Além disso, relatavam a forma como os professores explicavam os conteúdos e lidavam com os problemas em sala de aula.

\section{Atividade 2 - Confecção de pipas}

Nesta atividade, os acadêmicos planejaram uma aula para explorar conceitos de geometria por meio da construção de pipas. As quatro etapas foram bem destacadas nessa atividade, pois os acadêmicos fizeram o plano de aula, construíram pipas (Figura 1), pensando nos conceitos de geometria envolvidos (apresentados no Quadro 1), fizeram a exposição do trabalho aos alunos, inclusive construindo pipas com os mesmos e, por fim, foi feita a avaliação do trabalho.

Quadro 1 - Conceitos de Geometria abordados na construção de pipas (continuação)

\begin{tabular}{|l|l|}
\hline \multicolumn{1}{|c|}{ Conceitos abordados } & \multicolumn{1}{c|}{ Observações na Pipa } \\
\hline Perpendicularidade & Intersecção das varetas centrais \\
\hline Paralelismo & Bordas opostas \\
\hline Retas transversais & Varetas que cortam duas bordas paralelas \\
\hline
\end{tabular}


Quadro 1 - Conceitos de Geometria abordados na construção de pipas (conclusão)

\begin{tabular}{|l|l|}
\hline Congruência de triângulos & $\begin{array}{l}\text { Comparações entre as medidas dos lados dos } \\
\text { triângulos formados pelas varetas e as bordas }\end{array}$ \\
\hline Semelhança de triângulos & $\begin{array}{l}\text { Comparações entre as formas dos triângulos } \\
\text { formados pelas varetas e as bordas }\end{array}$ \\
\hline $\begin{array}{l}\text { Relações métricas no triângulo } \\
\text { retângulo }\end{array}$ & Projeções de um lado do triângulo sobre o outro \\
\hline
\end{tabular}

Fonte: Os autores.

Figura 1 - Confecção de pipas
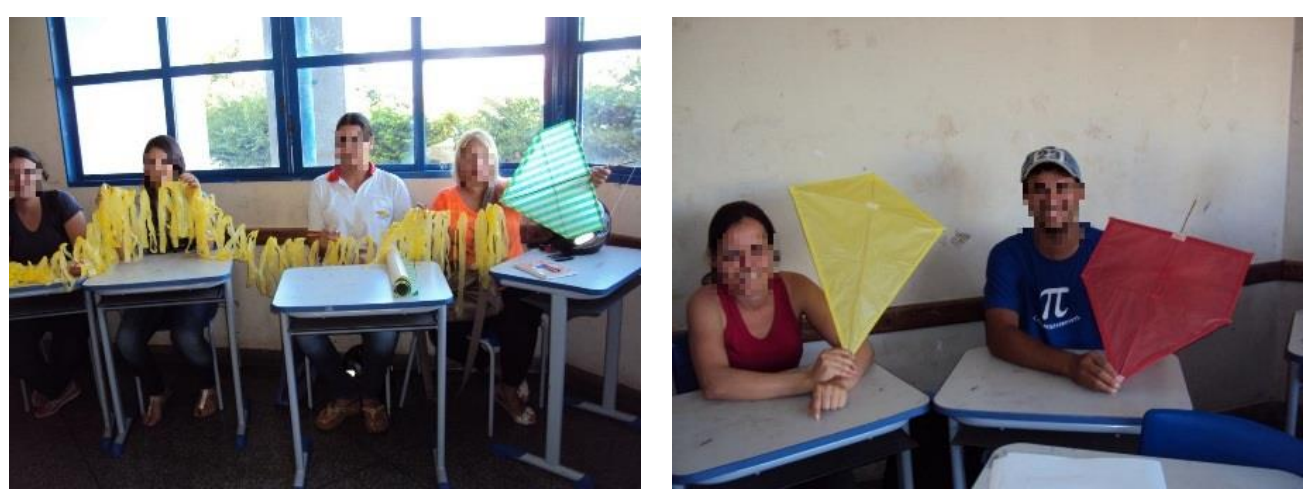

Fonte: Os autores.

\section{Atividade 3 - Feira de Matemática Itinerante}

A Feira de Matemática Itinerante se caracteriza por meio de uma mostra de materiais didáticos, jogos, curiosidades e desafios envolvendo conceitos matemáticos para alunos dos Ensinos Fundamental e Médio das escolas públicas e particulares da cidade de Cassilândia e em outros espaços, como feiras livres, praça central, lar dos idosos, etc. Ocorreram ainda apresentações nas cidades vizinhas de Itajá, Itarumã, Lagoa Santa e Aporé, no estado de Goiás, e Paranaíba e Chapadão do Sul em Mato Grosso do Sul. Por isso, estima-se que, ao longo dos anos, cerca de 150 pibidianos e mais de cinquenta mil expectadores participaram desse evento.

Os acadêmicos visitaram vários espaços públicos e privados levando materiais confeccionados por eles, que estão disponíveis no Laboratório de Ensino de Matemática - LEM, discutindo propriedades matemáticas presentes nestes materiais, evidenciando a necessidade de apresentar conceitos matemáticos por meio da ludicidade presente nos jogos, brincadeiras, desafios, quebra-cabeças, etc.

A feira de matemática itinerante se tornou importante no desenvolvimento de novas experiências, já que possibilitou ver o ensino de Matemática por outro ângulo, com momentos divertidos, motivando alunos a brincarem com conceitos e aprenderem utilizando determinado recurso. Dentro deste projeto foram apresentadas atividades que envolviam os seguintes materiais: tangrans (noções de geometria plana), escala cuisenaire (adição, subtração, divisão, multiplicação), disco de frações (adição e subtração de frações, frações equivalentes), torre de Hanói (função exponencial, 
concentração), dominó de frações (frações equivalentes), desafios envolvendo o teorema de Pitágoras (teorema de Pitágoras), aparato para construir elipse (elipse), blocos lógicos (classificação de formas, cores, tamanhos), sólidos geométricos (elementos de geometria espacial), cone ascendente (centro de massa), tabuleiro de Galton (distribuição binomial), material dourado (as quatro operações), plano cartesiano (localização de coordenadas), geoplano (construção de figuras planas), geoespaço (construção de figuras espaciais), jogo contig 60 (cálculo mental), jogo produto (multiplicação), jogo da velha 3D (raciocínio lógico), jogo da velha (concentração e raciocínio lógico), jogo do sobe e desce (adição e subtração de números inteiros), jogo feche a caixa (cálculo mental), jogo passa discos matemáticos (cálculo mental), jogo de xadrez (memória, concentração, planejamento e tomadas de decisões), quebra-cabeça: encaixe se for capaz (raciocínio lógico), etc.

A preparação dessa atividade teve início em 2013 e esteve em constante reformulação, pois sempre surgiam novos materiais a serem incorporados.

No planejamento, os bolsistas organizavam a forma de apresentação de cada material, havendo um revezamento entre eles para que todos pudessem apresentar todos os materiais. Desta forma, todos tinham a oportunidade de ganhar experiência.

A Figura 2 apresenta algumas imagens de materiais e atividades da Feira de Matemática Itinerante.

Figura 2 - Feira de Matemática Itinerante
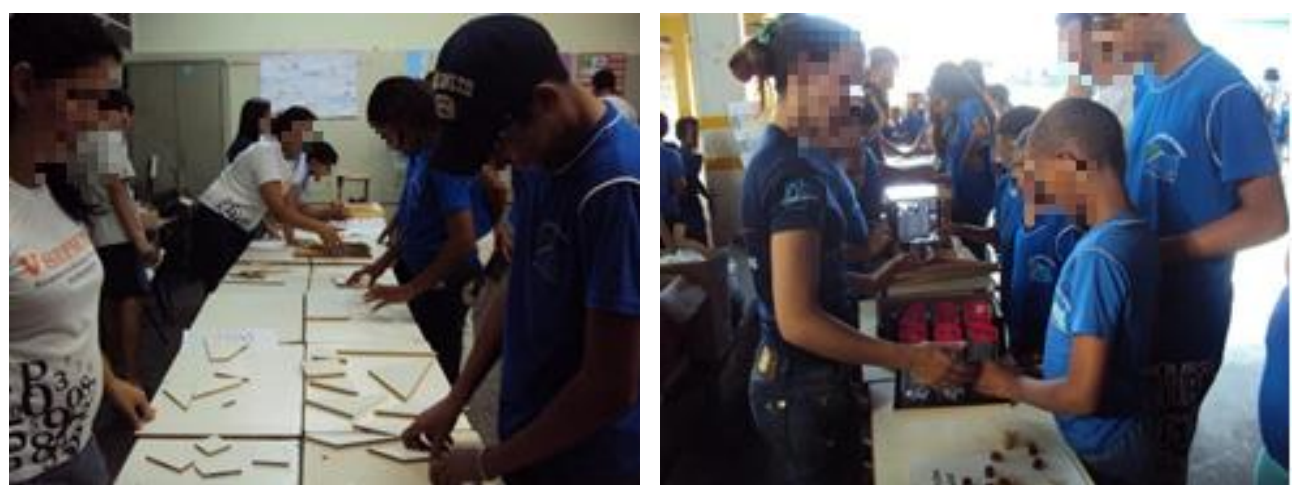

Fonte: Os autores.

\section{Atividade 4 - Sistema de numeração e operações aritméticas com números naturais em diferentes bases na prática}

Esta atividade foi retirada de Souza e Santos (2014), sendo que antes já havia sido executada pelo grupo de acadêmicos que participavam do PIBID da Universidade Federal de Mato Grosso do Sul no Campus de Três Lagoas. Nela, são apresentados os conceitos básicos de matemática envolvidos nos sistemas de numeração com diferentes bases numéricas e as operações básicas de aritmética utilizando um material 
didático adequado para que alunos e professores possam compreender com clareza os fundamentos do sistema de numeração de base dez.

Para a execução dessa tarefa, foram confeccionados kits compostos por caixas de diferentes dimensões para facilitar a visualização da representação numérica de quantidades nos sistemas de bases dois, três e quatro e a compreensão das operações de adição, subtração, multiplicação e divisão de números naturais. Depois de compreendida a representação dos números e o funcionamento das operações aritméticas básicas nestes três sistemas, ficou mais fácil estender os mesmos conceitos para o sistema de numeração de base dez. Um exemplo da representação do sistema de numeração de base dois é apresentado na Figura 3, onde se tem a representação binária do número 11 .

A execução desta atividade proporcionou êxito para todos os envolvidos no PIBID. Os acadêmicos, com a orientação dos coordenadores do PIBID, construíram os kits e os apresentaram a supervisores e alunos das escolas participantes. De acordo com os relatos em reuniões do grupo, esta atividade permitiu um melhor entendimento dos sistemas de numerações de maneira lúdica.

O planejamento e a elaboração dessa atividade duraram três meses e ela foi trabalhada com alunos dos anos finais do ensino fundamental e do ensino médio, sendo que ao todo cerca 1000 alunos e 30 acadêmicos bolsistas do PIBID participaram dela.

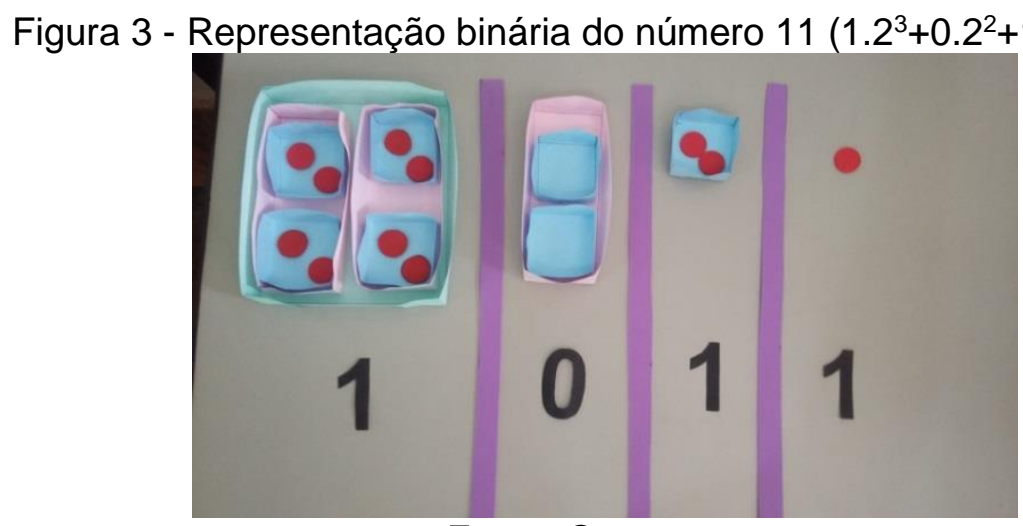

Fonte: Os autores.

\section{Outras Atividades}

Além das atividades já destacadas, os acadêmicos bolsistas do PIBID desenvolveram outras que também contribuíram para o aprendizado dos alunos das escolas atendidas. Estas atividades foram realizadas em turno contrário ao das aulas dos estudantes. Dentre elas citamos:

(a) o trabalho de reforço, durante todo o ano, com alunos dos Ensinos Fundamental e Médio que apresentavam dificuldades de aprendizagem, com a participação de cerca de 90 acadêmicos bolsistas do PIBID e 1500 alunos; os alunos eram escolhidos pelos professores de matemática, de acordo com as dificuldades 
apresentadas. Cada acadêmico ficava responsável por um grupo de até 10 alunos da mesma série. O acadêmico organizava os conteúdos que o professor pedia para trabalhar com esses alunos, revisava conteúdos, etc. Segundo relatos orais dos professores de matemática das escolas envolvidas, pelo menos $70 \%$ dos alunos participantes conseguiam melhorar seu desempenho em sala de aula.

(b) preparação de alunos para a Olimpíada Brasileira de Matemática das Escolas Públicas (OBMEP) e para o Exame Nacional do Ensino Médio (ENEM). Os acadêmicos preparavam as atividades nos três primeiros meses do ano e depois trabalhavam com os alunos até que essas provas acontecessem. Nas atividades da OBMEP participaram 12 pibidianos e cerca de 150 alunos, e para o ENEM participaram em torno de 20 pibidianos e cerca de 600 alunos. O Quadro 2, a seguir, apresenta as médias em matemática das escolas no ENEM no período citado nesse trabalho. As células sem notas se referem aos anos em que a escola não teve número suficiente de alunos para divulgação da nota. Observa-se que estas médias nem sempre cresceram com o passar dos anos, o que se justifica pelo fato de serem turmas diferentes.

No Quadro 3 são apresentadas as premiações obtidas na OBMEP por alunos da Escola São José entre os anos de 2011 e 2018. Das escolas participantes, a Escola São José era a que mais investia na preparação de alunos para a OBMEP. Porém, em 2016 e em 2017 a Escola Hermelina Barbosa Leal teve duas menções honrosas e em 2016 a Escola Rui Barbosa teve uma menção honrosa.

Quadro 2 - Médias de Matemática no ENEM das Escolas Participantes

\begin{tabular}{|l|c|c|c|c|c|c|c|c|}
\hline \multicolumn{1}{|c|}{ Escolas } & $\mathbf{2 0 1 1}$ & $\mathbf{2 0 1 2}$ & $\mathbf{2 0 1 3}$ & $\mathbf{2 0 1 4}$ & $\mathbf{2 0 1 5}$ & $\mathbf{2 0 1 6}$ & $\mathbf{2 0 1 7}$ & $\mathbf{2 0 1 8}$ \\
\hline São Jose & 457.24 & 467.43 & 497.65 & 455.23 & $\mathbf{4 4 5 . 2 9}$ & & 531 & 513.37 \\
\hline H. B. Leal & 495.34 & 452.21 & 503.3 & 469.17 & & & 456 & 489.46 \\
\hline R. Barbosa & & 447.01 & & & 435.61 & - & 452 & 541.52 \\
\hline
\end{tabular}

Fonte: Brasil, 2019

Quadro 3 - Premiação da OBMEP dos alunos da Escola São José

\begin{tabular}{|c|c|c|c|c|c|c|c|c|c|c|c|c|c|c|c|c|}
\hline Anos & \multicolumn{4}{|c|}{2011} & \multicolumn{4}{|c|}{2012} & \multicolumn{4}{|c|}{2013} & \multicolumn{4}{|c|}{2014} \\
\hline Medalhas & $\mathrm{O}$ & $\mathrm{P}$ & B & $\mathrm{M}$ & $\mathrm{O}$ & $\mathrm{P}$ & $B$ & $M$ & $\mathrm{O}$ & $\mathrm{P}$ & $\mathrm{B}$ & $\mathrm{M}$ & 0 & $\mathrm{P}$ & B & $\mathrm{M}$ \\
\hline total & - & - & 1 & 2 & - & 1 & 1 & 4 & - & - & 1 & 1 & - & - & 1 & 1 \\
\hline Anos & \multicolumn{4}{|c|}{2015} & \multicolumn{4}{|c|}{2016} & \multicolumn{4}{|c|}{2017} & \multicolumn{4}{|c|}{2018} \\
\hline Medalhas & 0 & $\mathrm{P}$ & $B$ & $\mathrm{M}$ & $\mathrm{O}$ & $P$ & $B$ & M & $\mathrm{O}$ & $\mathrm{P}$ & $\mathrm{B}$ & $M$ & 0 & $\mathrm{P}$ & $B$ & $\mathrm{M}$ \\
\hline total & - & 1 & 1 & 7 & - & - & 1 & 7 & - & - & 2 & 10 & - & - & - & 9 \\
\hline
\end{tabular}

Fonte: Olimpíadas Brasileira..., 2018.

(c) o campeonato de tabuada (Figura 4) foi realizado nas turmas do sexto ao nono ano, por meio de uma adaptação do jogo da memória. Foram confeccionados pelos pibidianos e alunos em torno de 30 grupos de fichas, em papel cartão, com a tabuada de multiplicação de 2 a 10 e com os resultados dos produtos. O campeonato foi realizado em cada sala de aula. No nível inicial, as primeiras rodadas eram realizadas com as 
fichas voltadas para cima, dessa forma os alunos podiam ver os registros e precisavam apenas formar os pares. Quando os alunos apresentavam um nível médio, o campeonato era realizado com as fichas voltadas para baixo. Nesses dois níveis o jogo era realizado individualmente, isto é, cada aluno utilizava entre 30 a 40 fichas. E quando os alunos apresentavam um nível mais avançado, o jogo era realizado em duplas, sendo que cada dupla compartilhava das mesmas cartas, como no tradicional jogo da memória. O vencedor era sempre o aluno que formava o maior número de pares. Esta atividade envolveu cerca de 820 alunos e 90 pibidianos.

Figura 4 - Campeonato de Tabuada

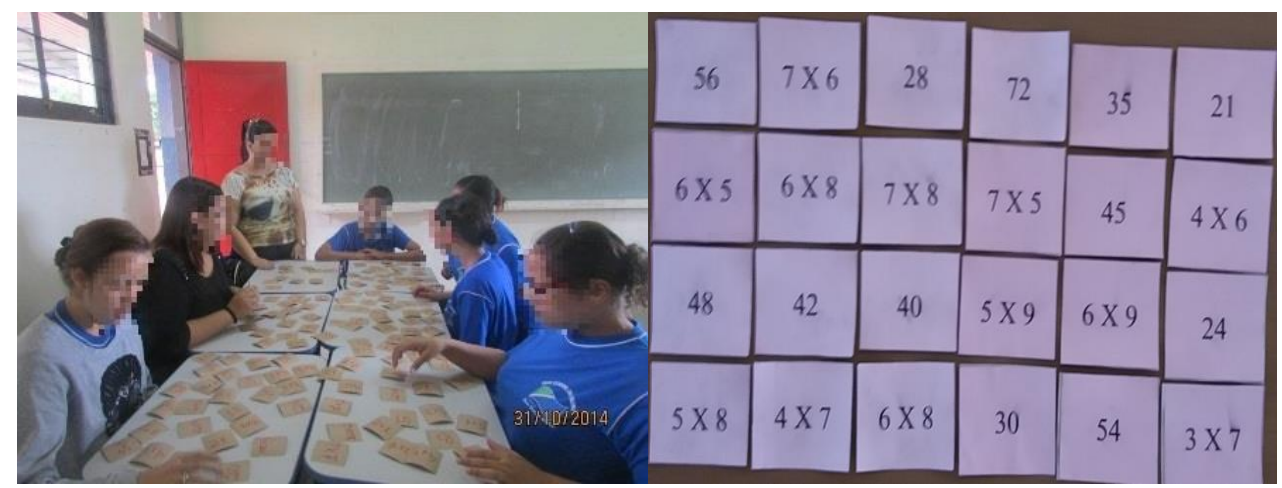

Fonte: Os autores.

\section{RESULTADOS E DISCUSSÃO}

As atividades do subprojeto de Matemática do PIBID da UEMS de Cassilândia foram propostas de forma a contribuir com a formação dos acadêmicos do curso, com melhoria do ensino e da aprendizagem dos alunos das escolas participantes, assim como aperfeiçoamento dos professores de matemática das escolas envolvidas. Tais atividades possibilitaram ensinar matemática de uma forma mais atrativa, provocando mais empatia entre acadêmicos, alunos e professores das escolas envolvidas.

$\mathrm{Na}$ atividade 1, ao estar presente na sala de aula, o pibidiano pode perceber os dilemas enfrentados pelos elementos que Wittter (2013) chama de figuras mais importantes no cenário educacional: o professor e o aluno. Ao professor cabe ensinar a matemática de forma a torná-la agradável ao aluno, prendendo sua atenção, mostrando sua utilidade e tornando o aluno agente ativo nesse processo. Ao aluno cabe dispor de vontade, ser participativo e colaborador para o bom andamento da aula. No meio desse processo esteve o pibidiano, observando e percebendo como essa relação se dá, se imaginando como professor e de que maneira agiria se estivesse no lugar deste, vislumbrando a sua atuação profissional.

A presença do PIBID nas escolas contribuiu com atividades diferenciadas: exploração de conceitos de geometria por meio da construção de pipas (Atividade 2), apresentação de jogos e materiais diversos para o ensino de matemática (Atividade 3), 
método prático para trabalhar sistemas de numeração (Atividade 4), prática da tabuada por meio de jogos (campeonato de tabuada), etc. Estas atividades estão de acordo com o que é proposto por Ponte e Quaresma (2015) quando dizem que há a necessidade de novas metodologias na apresentação dos conteúdos. Pode-se dizer que tais ações (atividades) foram propostas contributivas para suprir as necessidades e anseios do professor em resolver os problemas enfrentados no cotidiano de sala de aula, o que está de acordo com Souza e Estevez (2011).

Os professores supervisores tiveram a oportunidade de conviver com acadêmicos e coordenadores, assumindo funções dentro do subprojeto e utilizando o PIBID como um meio de formação continuada, conforme preconizam Marin e Franco (2014). Pois, Ihes foram proporcionados momentos de discussões de posturas, metodologias, estratégias para o desenvolvimento das aulas, contribuindo para que refletissem sobre suas práticas. Além disso, puderam ter contato com professores de outros subprojetos ou de outras escolas, onde puderam trocar experiências.

Embora não fosse meta do subprojeto do PIBID, mas das escolas, os resultados das ações do PIBID também contribuíram na melhoria em avaliações nacionais. Como mencionado anteriormente, o PIBID atuou em três escolas estaduais de Cassilândia, São José (2011-2018), Hermelina Barbosa Leal (2014-2018) e Rui Barbosa (20142018). Na Escola São José, o Índice de Desenvolvimento da Educação Básica (Ideb) do nível II (anos finais do ensino fundamental) melhorou consideravelmente a partir da entrada do PIBID na escola. Isto se aplica também para as outras duas escolas, embora tenham sido inseridas no subprojeto a menos tempo. As notas do Ideb no nível II entre 2007 e 2017 são apresentadas no Quadro 4. Em 2017 a Escola Hermelina Barbosa Leal não teve número suficiente de alunos para a avaliação.

Embora não sejam apresentadas as metas estipuladas para tais escolas, nos anos em que o PIBID esteve nelas, as notas obtidas foram superiores. Todas as notas das escolas e suas respectivas metas podem ser encontradas em http://ideb.inep.gov.br/resultado/.

Quadro 4 - Ideb das escolas participantes entre 2007 e 2017

\begin{tabular}{|c|c|c|c|c|c|c|}
\hline Ano/Escola & 2007 & 2009 & 2011 & 2013 & 2015 & 2017 \\
\hline H. B. Leal & 3,4 & 3,9 & 2,7 & 2,3 & 4,7 & \\
\hline R. Barbosa & 3,4 & 3,8 & 3,5 & 4,2 & 4,8 & 4,8 \\
\hline São José & 2,6 & 3,4 & 3,6 & 4,0 & 4,9 & 5,2 \\
\hline \multicolumn{7}{|c|}{ Fonte: Brasil, 2018 }
\end{tabular}

Ressalta-se que ao apresentar os resultados do ldeb, o objetivo aqui não é comparar as escolas, mas sim mostrar a evolução de cada escola com o passar dos anos. 


\section{CONCLUSÃO}

Neste trabalho buscou-se mostrar, por meio de algumas atividades desenvolvidas, como um subprojeto de Matemática do PIBID foi desenvolvido em escolas na Cidade de Cassilândia.

A inserção dos acadêmicos bolsistas do PIBID nas escolas faz com que eles vivenciem experiências docentes antes mesmo do Estágio Supervisionado. Passando a conhecer todas as dimensões de uma escola, seus problemas, êxitos, expectativas, responsabilidades que cada profissional possui no âmbito escolar e a necessidade do envolvimento da comunidade escolar no sucesso dos alunos na escola. Possibilitandoos refletir sobre a sua futura profissão, percebendo a necessidade da formação de professores críticos e reflexivos, que se preocupem com a formação geral do cidadão que confia na escola para trilhar a sua formação educacional.

Por meio das atividades desenvolvidas, os alunos das escolas participantes tiveram bons rendimentos em avaliações externas na área de matemática, conforme os dados apresentados do Ideb e do ENEM, ou mesmo na OBMEP. Porém ressalta-se que o foco do PIBID é o desenvolvimento profissional do acadêmico. De forma que tais resultados são apenas consequências do PIBID e não seu objetivo principal.

Em geral, as atividades do PIBID, da forma que foram colocadas contribuíram para a formação profissional e humana de todos os envolvidos, inclusive dos supervisores e coordenadores do subprojeto. Pois, estas aproximaram a universidade da escola, criando um clima favorável ao ensino, a aprendizagem e ao desenvolvimento de novas formas de ensino. Para os alunos bolsistas do subprojeto estas ações contribuíram para a formação acadêmica e experiência profissional. Pois, puderam também vivenciar práticas por meio da construção e manipulação de recursos que envolviam fundamentos da matemática e suas relações com o ensino.

\section{AGRADECIMENTOS}

Os autores agradecem a Coordenação de Aperfeiçoamento de Pessoal de Nível Superior (CAPES) pela concessão de bolsas aos Acadêmicos, Professores Supervisores e Coordenadores.

\section{REFERÊNCIAS}

ALVES-MAZZOTTI, J.; GEWANDSZNAJDER, F. O método nas ciências naturais e sociais: pesquisa quantitativa e qualitativa. 2. ed. São Paulo: Pioneira, 1999.

ARANDA, M. A. M. PIBID na UFGD, Ação, Reflexão, Ação. In: SIMPÓSIO BRASILEIRO DE POLÍTICA E ADMINISTRAÇÃO DA EDUCAÇÃO, 25., SIMPÓSIO 
IBERO-AMERICANO DE POLÍTICA E ADMINISTRAÇÃO DA EDUCAÇÃO, 2., 2011. Anais..., São Paulo, 2011.

BRAIBANTE, M. E.; WOLLMANN, E. M. A Influência do PIBID na Formação dos Acadêmicos de Química Licenciatura da UFSM. Química Nova Escola, v. 34, n. 4, p. 167-172, 2012.

BRASIL, CAPES. PIBID - Programa Institucional de Bolsa de Iniciação à

Docência. 2014. Disponível em: <http://www.capes.gov.br/educacaobasica/capespibid>. Acesso em: 14 jul. 2015.

BRASIL, Instituto Nacional de Estudos e Pesquisas Educacionais Anísio Teixeira IDEB: Resultados e Metas (2018). 2018. Disponível em:

<http://ideb.inep.gov.br/resultado/>. Acesso em: 28 ago. 2018.

BRASIL. Ministério da Educação. Microdados do Enem por Escola são divulgados pela primeira vez. Disponível em: http://portal.mec.gov.br/component/tags/tag/36409-enempor-escola. Acesso em: 2 fev. 2019.

CAMARGO, J. A. O PIBID no Cotidiano Profissional do Professor Supervisor de Matemática das Séries Finais do Ensino Fundamental. In: ENEM - ENCONTRO NACIONAL DE MATEMÁTICA - EDUCAÇÃO MATEMÁTICA: RETROSPECTIVAS E PERSPECTIVAS, 11., 2013. Anais..., Curitiba, 2013.

CAPPELIN, A.; SALOMÃO, M. E.; BEJARANO, S. R. W. S. Relato de Experiência dos Bolsistas PIBID Matemática do Colégio Estadual Professor Agostinho Pereira. In: ENCONTRO REGIONAL DE ESTUDANTES DE MATEMÁTICA DO SUL EREMATSUL, 17., 2011, Anais..., Curitiba, 2011.

CARRAHER, T.; CARRAHER, D.; SCHLIEMANN, A. Na vida dez, na escola zero. 3. ed. São Paulo: Cortez, 1989.

CAVALHEIRO, C. L. et al. A Inserção e as Ações do PIBID/UNIINFRA Subprojeto Pedagogia na Escola Walter Jobim. In: JORNADA NACIONAL DE EDUCAÇÃO, 16., 2012. Anais..., Santa Maria, 2012.

MARIN, V.; FRANCO, O. F. Análise dos Possíveis Impactos na Formação Continuada do Professor de Matemática por meio do Programa Institucional de Bolsas de Iniciação à Docência (PIBID). In: Revista Eletrônica Matemática e Estatística em Foco, v. 2, n. 1 , p. $1-13,2014$.

MIQUELIN, A. F. Joseph Wright. Pibid e a Formação de Professores de Física: Algumas Reflexões Pertinentes. Ensino \& Pesquisa - Revista Multidisciplinar de Licenciatura e Formação Docente, v. 12, n. 1, p. 101-114, 2014.

MELO, F. N. et al. PIBID: Experiências de Atividades Relacionadas ao Bullying. In: FIPED - FÓRUM INTERNACIONAL DE PEDAGOGIA - PESQUISA NA GRADUAÇÃO: Justiça Social, Diversidade e Emancipação Humana, 5., 2013. Anais..., Vitória da Conquista, 2013.

MOURA, M. O. et al. Atividade orientadora de ensino: unidade entre ensino $\mathrm{e}$ aprendizagem. Diálogo Educacional, v. 10, n. 29, p. 205-229, 2010. 
NEITZEL, A. A.; FERREIRA, V. S.; COSTA, D. Os impactos do Pibid nas licenciaturas e na Educação Básica. Conjectura: Filosofia e Educação, v. 18, p. 98- 121, 2013.

OLIMPÍADA BRASILEIRA DE MATEMÁTICA DAS ESCOLAS PÚBLICAS. Premiados da OBMEP. 2018. Disponível em: http://www.obmep.org.br/premiados.htm. Acesso em: 20 set. 2019.

PONTE, J. P; QUARESMA, M. Comunicação, tarefas e raciocínio: Aprendizagens profissionais proporcionadas por um estudo de aula. Zetetiké, v. 23, p. 297-310, 2015.

SARTORI, A. S. T; SCUCK, C. A.; BURIN, N. E. O PIBID na Formação de Professores de Matemática. In: JORNADA NACIONAL DE EDUCAÇÃO MATEMÁTICA, 4., JORNADA REGIONAL DE EDUCAÇÃO MATEMÁTICA, 17., 2012. Anais..., Passo Fundo, 2012.

SILVA, M. J. A. Como Alguns Estudantes do 9ำ Ano, Atendidos Pelo PIBID_UVA/2011 Percebem A Matemática. In: ENEM - ENCONTRO NACIONAL DE MATEMÁTICA EDUCAÇÃO MATEMÁTICA: RETROSPECTIVAS E PERSPECTIVAS, 11., 2013. Anais..., Curitiba, 2013.

SOUZA, N. M. M.; ESTEVEZ, A. K. Interações entre Pesquisa Acadêmica e Formação Continuada: os conhecimentos de um grupo de professores sobre números decimais. In: SOUZA, N. M. M; ESPÍNDOLA, A. L. (Orgs.). Experiências de Formação de Professores: Ensino, Pesquisa e Extensão. Campo Grande: Ed. UFMS, 2011, p. 2750, 2011.

SOUZA, F. P. de; SANTOS, R. R. dos (Orgs.). Interciências: Investindo em Novos Talentos da Rede de Educação Pública para Inclusão social e Desenvolvimento da Cultura Científica em Três Lagoas-MS. Campo Grande: Ed. UFMS, 2014.

WITTER, G. P. Professor-estresse: análise de produção científica. Psicologia Escolar e Educacional, v. 7, n. 1, p. 33-46, 2013. 